\title{
Análise sensorial de músculo de mapará com e sem tratamento osmótico
}

\author{
Sensorial evaluation of mapará muscle with and without osmotic treatment
}

\author{
Suezilde da Conceição Amaral RIBEIRO ${ }^{1}$, Kil Jin PARK², Miriam Dupas HUBINGER ${ }^{3}$, \\ Carmelita de Fátima Amaral RIBEIRO ${ }^{2 \star}$, Eder Augusto Furtado ARAUJO ${ }^{4}$, Satoshi TOBINAGA ${ }^{3}$
}

\section{Resumo}

O objetivo deste trabalho foi avaliar sensorialmente o mapará in natura e com pré-tratamento osmótico antes da secagem. Para o teste de aceitabilidade do bolinho de músculo de mapará, foram utilizados peixes in natura e desidratados osmoticamente, nas melhores condições de processo, em soluções de $\mathrm{NaCl}, \mathrm{NaCl}+$ sacarose e em solução de $\mathrm{NaCl}+$ xarope de milho e secos. Foram utilizados 25 provadores não treinados, de ambos os sexos, com idade variando de 20 a 60 anos. Os atributos sensoriais avaliados foram aparência, aroma, sabor, textura e impressão global. O aroma e a textura das amostras com e sem pré-tratamento osmótico foram os atributos que obtiveram maior aceitação por parte dos consumidores. Pôde-se concluir que as amostras tratadas com soluções osmóticas, com exceção das tratadas com solução de $\mathrm{NaCl}+$ xarope de milho, proporcionaram produtos com textura, sabor e aroma mais agradáveis.

Palavras-chave: sabor; peixe; desidratação; xarope.

\begin{abstract}
The objective of this work was the sensorial evaluation of mapará meat, in natura and without osmotic pre-treatment before drying. For the acceptability test of the mapará fish muscle bisquit, the in natura fish samples were used and dried under optimum osmotic dehydration conditions, in solutions of $\mathrm{NaCl}, \mathrm{NaCl}+$ sucrose and in solution of $\mathrm{NaCl}+$ corn syrup solution before drying. 25 not trained testers were used, of both sex, ages ranging from 20 to 60 years. The evaluated sensorial attributes of the samples were appearance, aroma, flavor, texture and overall impression. The aroma and texture of the samples with and without osmotic pre-treatment were the ones most widely accepted by the consumers. It is concluded that the samples treated with osmotic solutions, with the exception of those processed with $\mathrm{NaCl}+\mathrm{corn}$ syrup solution, provided products with better texture, flavor and a more pleasant aroma.
\end{abstract}

Keywords: flavor; fish; dehydration; syrup.

\section{Introdução}

O mapará (Hypophthamus edentatus) é uma matéria-prima de interesse econômico, porém, da mesma forma que outros peixes lisos, o consumo no Amazonas é baixo devido a tabus alimentares, sendo a maioria da produção comercializada para outros países e Estados do Brasil (CUTRIM, 2005).

O peixe salgado desidratado é um produto alimentício de grande procura em diversas partes do mundo, constituindo um produto nobre de alto valor agregado, como por exemplo, o bacalhau. De modo geral, estes produtos salgados desidratados não necessitam de refrigeração para sua conservação, o que implica em redução de custos de transporte e armazenamento (MEDINA VIVANCO, 2003).

Para garantir a qualidade do pescado, é necessário ter um manuseio correto desde a captura, acondicionamento e comercialização. Durante a produção e o armazenamento do pescado e de seus subprodutos, a rancificação e a contaminação por micro-organismos diminuem o tempo de prateleira do produto e podem causar efeitos indesejáveis ao alimento e, consequentemente, à saúde. Com isto, há necessidade do controle de qualidade destes produtos através de métodos químicos, microbiológicos e sensoriais (STEVANATO et al., 2007).

A desidratação osmótica é um método de remoção parcial de água dos alimentos. Baseia-se na imersão dos alimentos em soluções hipertônicas de um ou mais solutos, originando dois fluxos simultâneos e opostos: uma saída de água do produto para a solução e uma migração de solutos da solução para o produto. A saída de sólidos naturais do alimento é quantitativamente desprezível, embora possa ser importante no que diz respeito às características sensoriais e nutricionais (TONON, et al., 2006).

Segundo Ramallo et al. (2007), as transformações físicas e químicas que ocorrem no alimento durante o processo de desidratação osmótica afetam as características macroscópicas dos tecidos, tais como cor, aparência e textura, em diferentes medidas de acordo com as condições de processo e natureza do produto.

Recebido para publicação em 20/2/2008

Aceito para publicação em 3/1/2009 (003059)

${ }^{1}$ Escola Agrotécnica Federal de Castanhal, BR 316, Km 62, CEP 68740970, Castanhal - PA, Brasil, E-mail: suzi@eafc-pa.gov.br

${ }^{2}$ Faculdade de Engenharia Agrícola - UNICAMP, Cidade U. Zeferino Vaz, CP 6011, CEP 13083-875, Campinas - SP, Brasil, E-mail: carmelita.ribeiro@agr.unicamp.br

3 Faculdade de Engenharia de Alimentos - UNICAMP, Campinas - SP, Brasil, E-mail: mhub@fea.unicamp.br

4 Departamento de Engenharia Química e de Alimentos - Universidade Federal do Pará, E-mail: earaujo@ufpa.br

${ }^{*}$ A quem a correspondência deve ser enviada 
A análise sensorial destaca-se na avaliação da qualidade e estabilidade de diversos produtos porque nenhum teste instrumental ou químico pode substituir os receptores sensoriais. Os métodos objetivos medem algum fator indicativo da oxidação, como produtos de decomposição, mas apenas a avaliação sensorial quantifica a percepção total de intensidade de sabor ou de qualidade.

O objetivo do trabalho foi caracterizar sensorialmente o mapará in natura e com pré-tratamento osmótico antes da secagem.

\section{Material e métodos}

\subsection{Análises físico-químicas}

Após a desidratação osmótica e secagem do pescado, foram realizadas as determinações de açúcares totais, cloretos, número de ácido tiobarbitúrico (TBA) e atividade de água.

Os açúcares totais foram determinados de acordo com o método de Munson e Walker (AOAC, 1995), que consiste na redução do cobre presente na solução de Fehling através de açúcar invertido. O conteúdo de açúcar foi estimado pelo volume de solução de açúcar necessário para reduzir completamente a solução de Fehling de volume conhecido.

A determinação de cloretos foi feita através da quantificação de íons $\mathrm{Cl}^{-}$, seguindo o método de titulação direta com $\mathrm{AgNO}_{3}$, utilizando $\mathrm{K}_{2} \mathrm{CrO}_{4}$ como indicador segundo o Método de Mohr (AOAC, 1995).

O número de ácido tiobarbitúrico (TBA) foi determinado de acordo com a metodologia de Tarladgis et al. (1960). Os destilados obtidos foram submetidos à reação de cor com ácido 2-tiobarbitúrico e lidos em espectrofotômetro a $532 \mathrm{~nm}$.

A Atividade de água $\left(a_{w}\right)$ foi realizada utilizando aparelho analisador de atividade de água, Decagon, série 3TE, que aplica o princípio do ponto de orvalho, no qual a água é condensada em superfície espelhada e fria e detectada por sensor infravermelho.

\subsection{Matéria-prima}

Os exemplares de mapará (Hypophthamus edentatus) foram adquiridos na EDIFRIGO Comercial Industrial (Santarém -Pará) e transportados até o Laboratório de Medidas Físicas da Faculdade de Engenharia de Alimentos da Universidade Estadual de Campinas onde foram previamente lavados (com água clorada), eviscerados, embalados em sacos plásticos e congelados a $-18^{\circ} \mathrm{C}$.

As amostras foram obtidas com o auxílio de um cortador de aço inox, desenvolvido para se obter placas de $3 \mathrm{~cm}$ de comprimento e $2 \mathrm{~cm}$ de largura. Após a obtenção das placas, as amostras eram submetidas a um novo corte, em cortador também projetado para este fim, com o objetivo de se obter placas com uma espessura de $0,5 \mathrm{~cm}$.

\subsection{Desidratação osmótica}

As amostras foram pesadas e colocadas em béquer de vidro de $600 \mathrm{~mL}$, contendo solução aquecida à temperatura de processo. Foram utilizadas três agentes desidratantes: $\mathrm{NaCl}$, sacarose comercial e xarope de milho MOR-REX 1940 (Corn Products Brasil). A relação amostra/solução de 1:5 foi utilizada para garantir a concentração constante da solução osmótica. O conjunto amostra-solução desidratante foi então levado à incubadora refrigerada (shaker) mantida na temperatura de estudo e agitação constante de $80 \mathrm{rpm}$.

Foi realizada a otimização do processo osmótico dos filés de mapará como pré-tratamento de secagem, utilizando a Metodologia de Superfície de Resposta (RSM). A melhor condição de processamento de desidratação foi encontrada através da sobreposição dos gráficos de GS/PA para maximizar a perda de água e minimizar o ganho de sólidos.

As condições escolhidas na otimização do processo osmótico foram: temperatura de $46^{\circ} \mathrm{C}$, concentração de $22 \%$ e tempo de imersão de 7 horas para desidratação com solução de $\mathrm{NaCl}$ (dentre os experimentos realizados na faixa de temperaturas de 23 a $57^{\circ} \mathrm{C}$, concentrações de $\mathrm{NaCl}$ de 20 a $26 \%$ e tempos de 4 a 14 horas); $42{ }^{\circ} \mathrm{C}$ de temperatura, $11,5 \%$ de concentração de sal, $30 \%$ de concentração de açúcar e tempo de 8 horas, para desidratação com solução de $\mathrm{NaCl}+$ sacarose (dentre os experimentos realizados na faixa de temperaturas de 23 a $57^{\circ} \mathrm{C}$, concentrações de $\mathrm{NaCl}$ de 11,3 a 14,7\%, concentração de sacarose constante de $30 \%$ e tempos de 4 a 14 horas); e $46{ }^{\circ} \mathrm{C}$ de temperatura, $13 \%$ de concentração de sal, $32,5 \%$ de concentração de xarope de milho e tempo de 6 horas para desidratação com solução de $\mathrm{NaCl}+$ xarope de milho (dentre os experimentos realizados na faixa de temperaturas de 20 a $60^{\circ} \mathrm{C}$, concentrações de $\mathrm{NaCl}$ de 11 a 15\%, concentrações de xarope de 25 a $45 \%$ e tempos de 3 a 15 horas).

\subsection{Secagem}

As amostras in natura e a melhor condição de desidratação osmótica, para as três soluções de $\mathrm{NaCl}, \mathrm{NaCl}+$ sacarose e $\mathrm{NaCl}+$ xarope de milho, foram submetidas ao processo de secagem até alcançarem massa constante. As variáveis de processo de secagem foram temperaturas $\left(40,50\right.$ e $\left.60^{\circ} \mathrm{C}\right)$ e velocidade do ar de secagem (1,5 m/segundo), realizado num secador de bandejas.

\subsection{Análise sensorial}

Para a análise sensorial, foram elaborados bolinhos de peixe com as amostras desidratadas (condições otimizadas) secas (até a obtenção do produto com $40 \%$ de umidade) e também com a amostra in natura, com o mínimo de ingredientes possíveis, tendo como objetivo não mascarar o sabor do peixe. Os ingredientes utilizados na formulação do bolinho foram: carne de pescado $(49,7 \%)$, batata cozida amassada $(49,7 \%)$, cebola desidratada $(0,4 \%)$ e alho desidratado $(0,2 \%)$. Os bolinhos foram fritos a uma temperatura de $180^{\circ} \mathrm{C}$, em uma fritadeira marca Fritanella Walitta com registrador de temperatura por 2,15 minutos (tempo e temperatura determinados a partir de testes preliminares). 


\subsection{Teste de aceitabilidade}

Realizou-se o teste de aceitabilidade com uma escala hedônica não estruturada de $9 \mathrm{~cm}$ referente aos atributos aparência, aroma, sabor, textura e impressão global ancorado em seus extremos com os termos "desgostei extremamente" (1) até "gostei extremamente" (9). Cada julgador tinha que avaliar, para cada amostra, os atributos e também indicar sua intenção de compra diante de cada amostra avaliada, em uma escala de cinco pontos que variava de "certamente não compraria" (1) a "certamente compraria" (5) de acordo com Antunes (2004).

O teste foi realizado por uma equipe de 25 provadores não treinados, de ambos os sexos, alunos de graduação e pós-graduação da Faculdade de Engenharia de Alimentos da Universidade Estadual de Campinas com idade variando de 20 a 60 anos.

Os testes foram realizados em cabines individuais no Departamento de Alimentos e Nutrição (DEPAN) da UNICAMP. Cada provador, de acordo com o procedimento experimental, recebeu uma amostra codificada de cada vez (apresentação monádica) juntamente com a ficha de avaliação. As amostras foram servidas em pratos brancos de plástico, à temperatura de aproximadamente $40-45^{\circ} \mathrm{C}$. Entre o intervalo de análise de cada amostra foram oferecidas bolachas (água e sal) e água.

\subsection{Análise estatística}

Os resultados obtidos na análise sensorial foram submetidos à análise de variância (ANOVA), e as médias foram comparadas pelo teste de Tukey ao nível de $5 \%$ de significância, utilizando o software STATISTICA 5.0.

\section{Resultados e discussão}

\subsection{Análises físico-químicas}

As amostras secas sem pré-tratamento e com prétratamento até a umidade de equilíbrio foram avaliadas através da determinação de cloretos, açúcares totais, TBA e atividade de água. Os resultados das análises estão apresentados na Tabela 1.

Observa-se na Tabela 1 que as amostras desidratadas com solução de $\mathrm{NaCl}$ apresentaram umidade e atividade de água menor que as amostras sem pré-tratamento e desidratadas com solução ternária. Porém as amostras desidratadas com solução de $\mathrm{NaCl}$ apresentaram uma maior oxidação em relação às amostras desidratadas com solução ternária.

As amostras sem tratamento sofreram uma oxidação bem maior, quando comparadas com as amostras que sofreram tratamento, significando que o tempo de secagem interferiu mais na resposta que a concentração de $\mathrm{NaCl}$. A atividade de água praticamente não foi reduzida nas amostras sem pré-tratamento, comprovando, portanto, o efeito positivo da utilização da desidratação osmótica como pré-tratamento na redução da atividade de água.

Verifica-se que as amostras desidratadas com solução de $\mathrm{NaCl}+$ sacarose apresentaram valores de açúcares totais maiores do que os encontrados pelas amostras de $\mathrm{NaCl}+$ xarope. Apesar das amostras não possuírem os mesmos níveis de parâmetros de desidratação, pode-se afirmar que as amostras desidratadas com solução de $\mathrm{NaCl}+$ sacarose apresentaram estes valores devido à competitividade que a sacarose, um dissacarídeo, tem com o $\mathrm{NaCl}$.

Segundo Stevanato et al. (2007), a oxidação lipídica é a deterioração oxidativa de ácidos graxos, que pode ser iniciada por via enzimática (ação da lipoxigenase) ou não enzimática, por fatores como calor, luz, oxigênio, traços de metais, etc.

Os pescados apresentam condições intrínsecas que propiciam a multiplicação microbiana, podendo reduzir a vida útil do produto que passará a representar risco à saúde pública. A elevada atividade de água, a composição química, o teor de gorduras insaturadas facilmente oxidáveis e o $\mathrm{pH}$ próximo da neutralidade da carne de peixe são os fatores determinantes no crescimento microbiano (OLIVEIRA et al., 2008).

Tabela 1. Resultados das análises físico-químicas dos produtos finais.

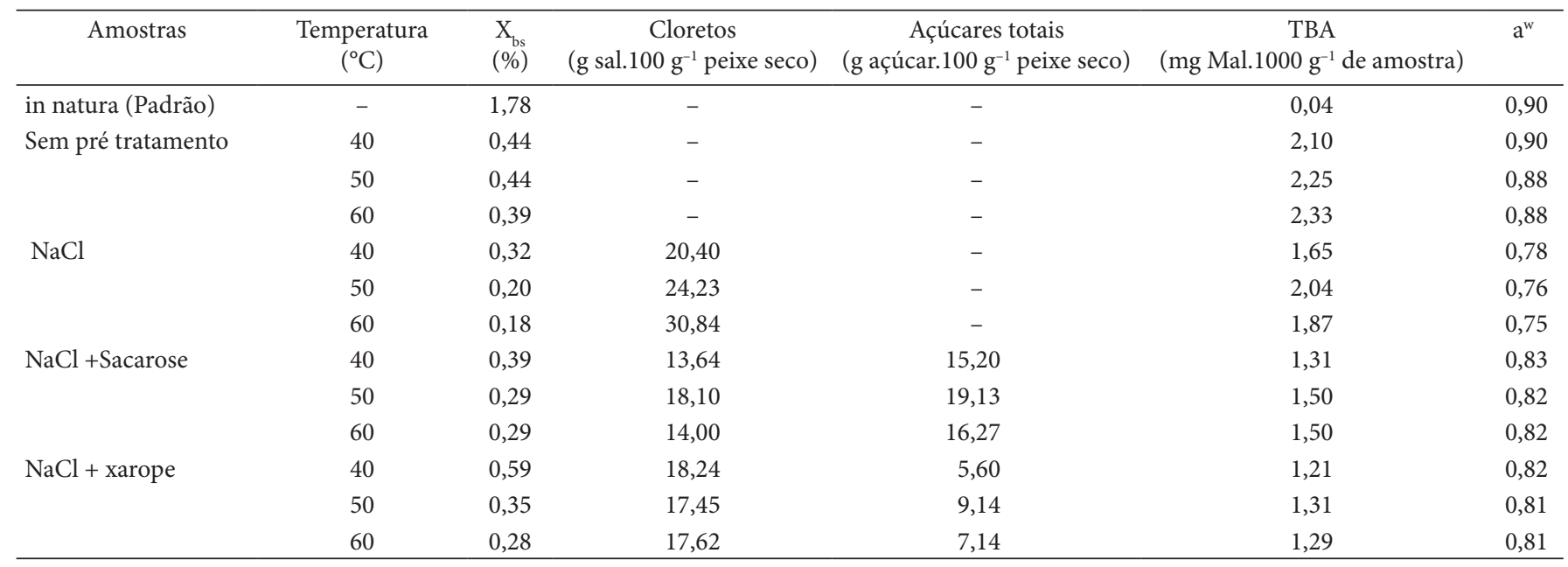


Sampaio (2004) determinou a ocorrência de produtos da oxidação do colesterol ao analisar o perfil lipídico em camarão salgado-seco. Os resultados para o perfil de ácidos graxos corresponderam a $27,48,43,90$ e $28,61 \%$ para saturados, monoinsaturados e poli-insaturados, respectivamente. Este estudo indicou que as amostras estavam oxidadas, tanto pela presença de produtos da oxidação do colesterol como pelos valores de $\mathrm{TBAR}_{\mathrm{S}}$. Tal oxidação foi, provavelmente, iniciada no processamento e em condições inadequadas de armazenamento. Os resultados reforçaram a importância da reavaliação dos procedimentos que envolvem o manuseio de pescados, particularmente do camarão salgado-seco, desde a captura até a determinação do tempo de prateleira, no sentido de minimizar as reações oxidativas.

\subsection{Análise sensorial}

O perfil dos consumidores que participaram do Teste de Aceitabilidade de bolinho de peixe mapará in natura e desidratado seco é mostrado na Figura 1. Verifica-se que a maioria dos provadores que participaram do teste era do sexo feminino, com faixa etária entre 20 e 30 anos.

Na Tabela 2, estão os resultados da Análise de Variância para a aparência, aroma, sabor, textura e impressão global das amostras de bolinho de peixe mapará sem tratamento (in natura) e pré-tratados em solução binária de $\mathrm{NaCl}$ e soluções ternárias de $\mathrm{NaCl}+$ sacarose e $\mathrm{NaCl}+$ xarope de milho.

\section{Atributo aparência}

Os provadores não notaram diferenças $(\mathrm{p}<0,05)$ quanto à aparência das amostras, para as quatro formulações (Tabela 2a).
A distribuição das notas de aceitação de cada uma das amostras para o atributo aparência está apresentada na Figura 2.

Observa-se na Figura 2 que a maioria das notas recebidas pelas amostras sem tratamento e pré-tratadas osmoticamente com soluções binárias e ternárias situa-se na região indicativa de aprovação dos produtos, ou seja, valores iguais ou acima de 5 , sendo que a amostra pré-tratada osmoticamente em solução de $\mathrm{NaCl}+$ xarope de milho foi a que apresentou o menor índice de aceitação entre as quatro amostras avaliadas $(79,16 \%$ de aceitabilidade) e a amostra sem tratamento apresentou maior índice $(84,18 \%$ de aceitabilidade).

\section{Atributo aroma}

A Tabela $2 \mathrm{~b}$ mostra que para o atributo aroma todas as amostras apresentaram diferença entre si, a $p<0,05$. Os resultados agregados do teste de média para aroma estão apresentados na Tabela 2.

A distribuição das notas de aceitação de cada uma das amostras para o atributo aroma está apresentada na Figura 3.

Observa-se, na Figura 3, que a maioria das notas recebidas pelas amostras sem tratamentos e pré-processadas osmoticamente com soluções binárias e ternárias situa-se na região indicativa de aprovação dos produtos, sendo que a amostra sem tratamento $(87,87 \%)$ foi a que apresentou o maior índice de aceitabilidade, seguida da amostra pré-tratada com solução de $\mathrm{NaCl}(82,36 \%)$.

Borges et al. (2007) avaliaram a qualidade da corvina (Micropogonias furnieri) eviscerada em diferentes períodos de estocagem a $0{ }^{\circ} \mathrm{C}$. Os atributos aroma característico de peixe marinho, lembrando algas marinhas, e aroma de maresia apresentaram relação inversamente proporcional, ou seja,
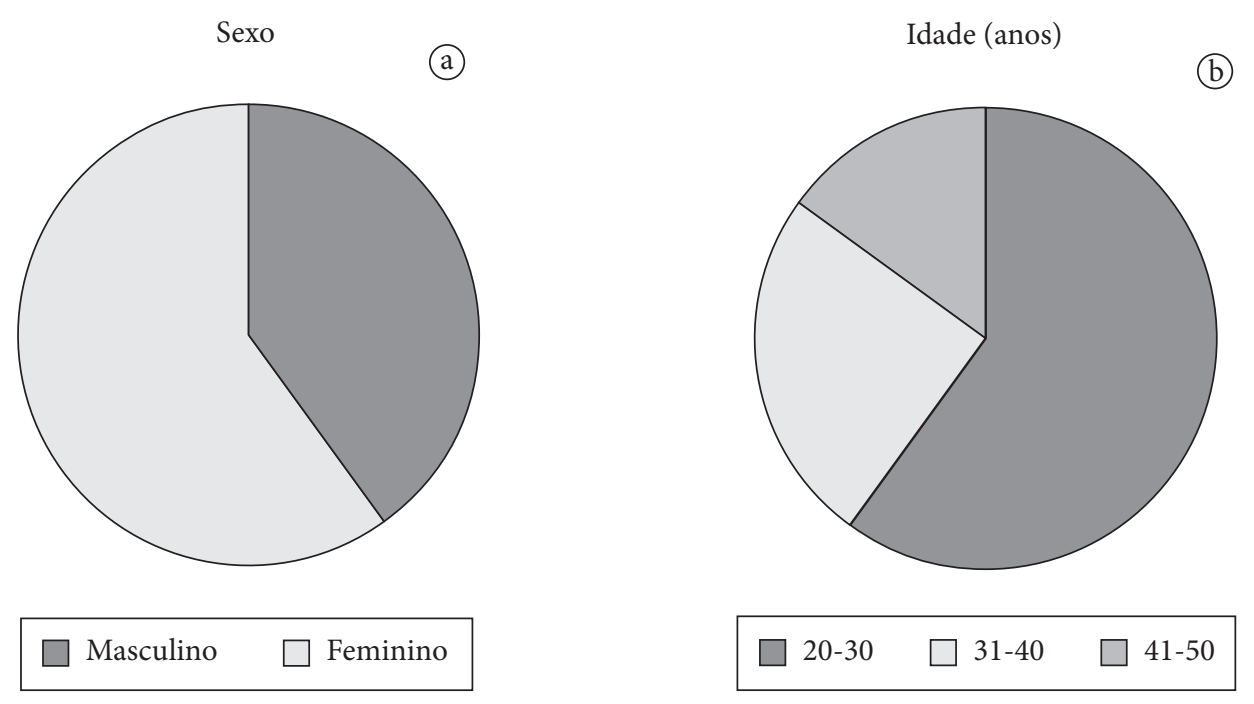

Figura 1. Sexo (1a) e idade (1b) dos provadores utilizados no teste de aceitabilidade de bolinho de peixe mapará com e sem tratamento osmótico. 
na corvina recém-capturada (dia 0 ), o aroma característico era evidente, diminuindo conforme aumentou o tempo de estocagem; ocorrendo o contrário com o aroma de maresia. $\mathrm{O}$ mesmo ocorreu com os atributos gosto amargo e gosto doce: na corvina recém-capturada, o gosto amargo não era percebido, enquanto o gosto doce era bem evidente.

\section{Atributo sabor}

Para o atributo sabor (Tabela $2 c$ ), houve diferença significativa na aceitação das amostras $(\mathrm{p}<0,05)$. Os resultados agregados do teste de média para sabor estão apresentados na Tabela 3.

A distribuição das notas de aceitação de cada uma das amostras para o atributo sabor está apresentada na Figura 4.

Observa-se, na Figura 4, que a maioria das notas recebidas pelas amostras sem tratamento (76,93\% de aceitabilidade) e pré-tratadas osmoticamente com soluções de $\mathrm{NaCl}(74,98 \%$ de aceitabilidade) e $\mathrm{NaCl}+$ sacarose (70,71\% de aceitabilidade) situam-se na região indicativa de aprovação dos produtos, exceto a amostra com solução de $\mathrm{NaCl}+$ xarope de milho que

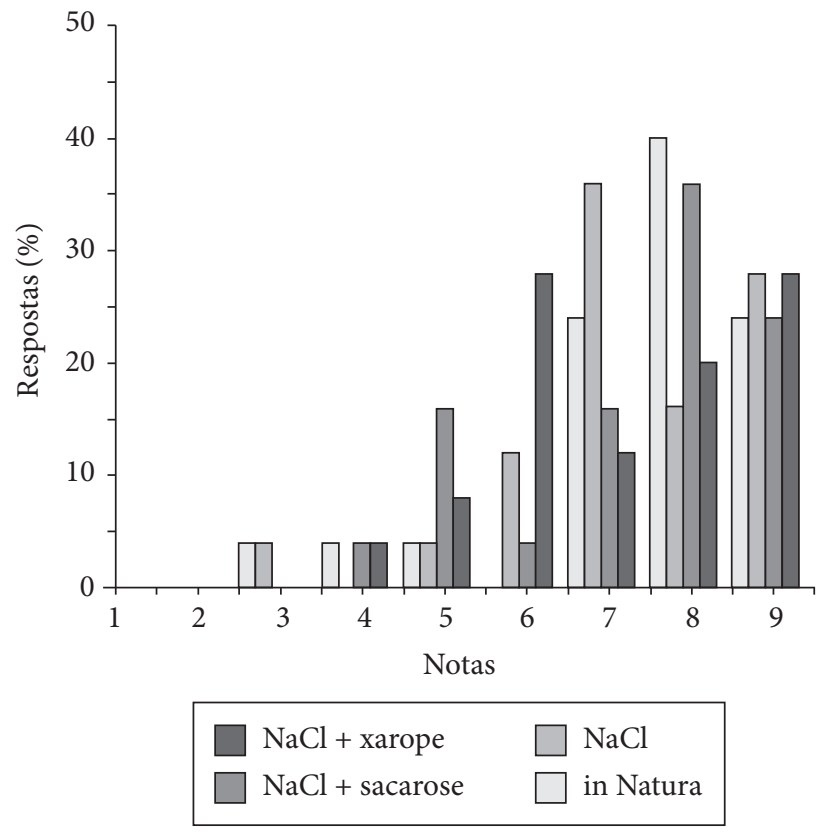

Figura 2. Histograma de frequência dos valores atribuídos à aparência das amostras de bolinho de peixe mapará com e sem tratamento osmótico.

Tabela 2. Análise de variância (ANOVA) de acordo com a resposta.

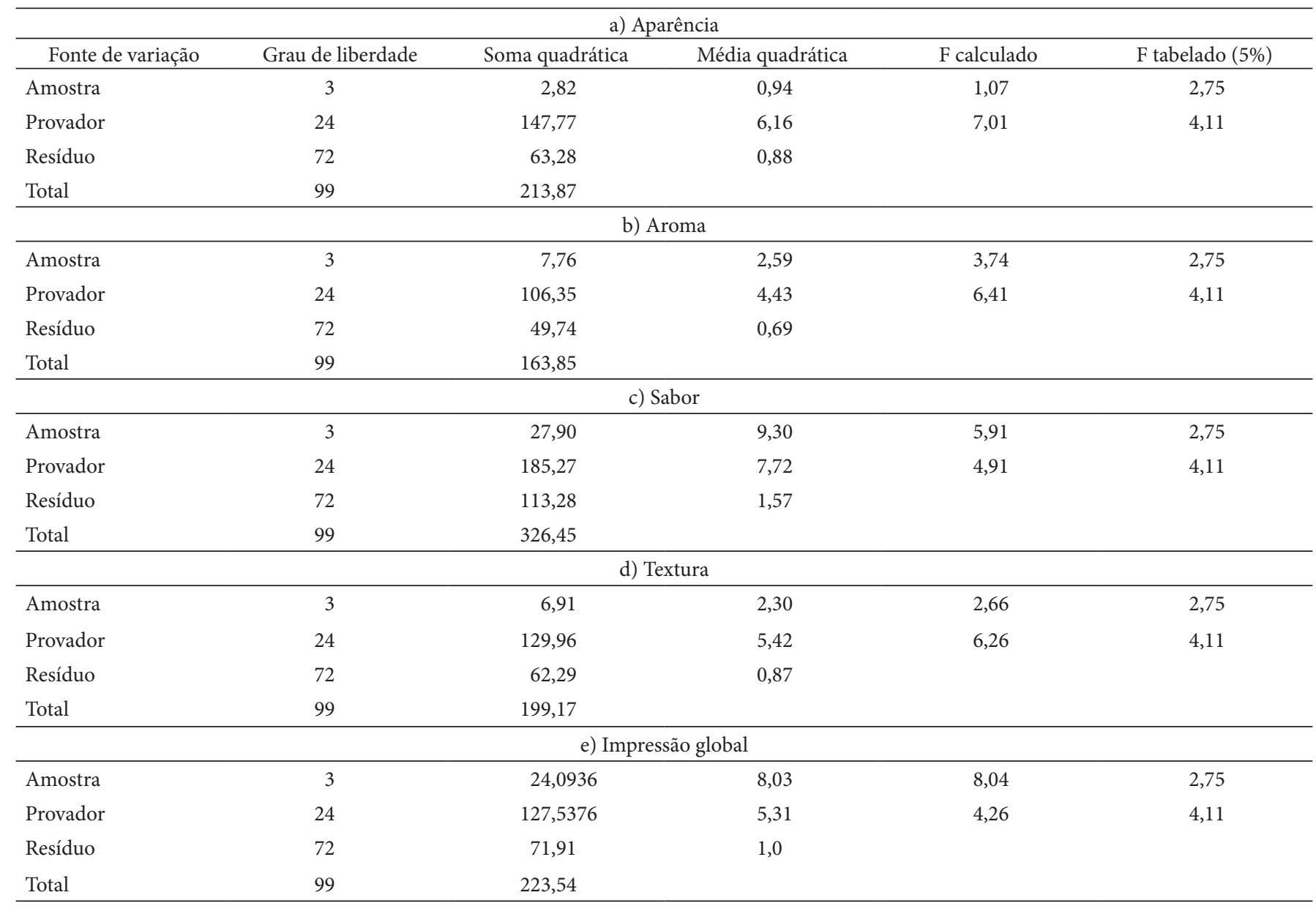




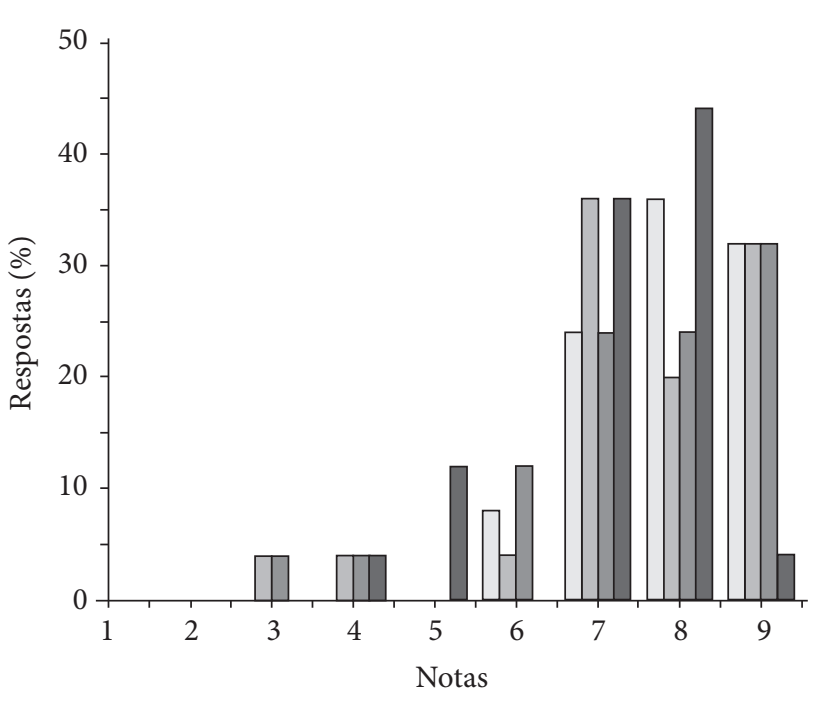

$\begin{array}{|ll|}\square \mathrm{NaCl}+\text { xarope } & \square \mathrm{NaCl} \\ \square \mathrm{NaCl}+\text { sacarose } & \square \text { in Natura }\end{array}$

Figura 3. Histograma de frequência dos valores atribuídos ao aroma das amostras de bolinho de peixe mapará com e sem tratamento osmótico.

Tabela 3. Aceitação média dos atributos aparência, aroma, sabor, textura e impressão global de "bolinho de peixe mapará" seca com e sem pré-tratamento osmótico.

\begin{tabular}{lcccc}
\hline \multicolumn{1}{c}{ Atributo } & in natura & $\mathrm{NaCl}$ & Sacarose & Xarope de milho \\
\hline Aparência & $7,58^{\mathrm{a}}$ & $7,30^{\mathrm{a}}$ & $7,22^{\mathrm{a}}$ & $7,12^{\mathrm{a}}$ \\
Aroma & $7,91^{\mathrm{a}}$ & $7,41^{\mathrm{a}, \mathrm{b}}$ & $7,34^{\mathrm{a}, \mathrm{b}}$ & $7,15^{\mathrm{b}}$ \\
Sabor & $6,92^{\mathrm{a}}$ & $6,75^{\mathrm{a}}$ & $6,36^{\mathrm{a}, \mathrm{b}}$ & $5,55^{\mathrm{b}}$ \\
Textura & $7,4^{\mathrm{a}}$ & $6,98^{\mathrm{a}}$ & $7,14^{\mathrm{a}}$ & $6,68^{\mathrm{a}}$ \\
Impressão global & $7,48^{\mathrm{a}}$ & $7,33^{\mathrm{a}, \mathrm{c}}$ & $6,65^{\mathrm{b}, \mathrm{c}}$ & $6,28^{\mathrm{b}}$ \\
\hline
\end{tabular}

Obs: Médias com letras em comum na mesma linha não diferem significativamente entre si com nível de significância de $5 \%$.

apresentou $61,69 \%$ de aceitabilidade, valor considerado baixo para indicar que o produto foi aceito pelos provadores.

Cerca de $36 \%$ dos provadores destacaram um "sabor de terra" ou de "peixe velho" na amostra com solução de $\mathrm{NaCl}+$ xarope de milho, o que pode explicar a sua baixa aceitabilidade. Estes tipos de sabores são mais evidentes em peixe de água doce, como o mapará.

Neiva et al. (2002) elaboraram o produto linguiça de peixe, utilizando carne mecanicamente separada (CMS), ou polpa de peixes de baixo valor comercial, além de avaliar sua composição e sua aceitação pelos consumidores. Na avaliação sensorial, a linguiça avaliada recebeu pontuações, para todos os atributos, entre "gostei um pouco e gostei muito": $68 \%$ dos consumidores consideraram o produto com sabor ideal de peixe; $24 \%$ dos consumidores estavam em dúvida quanto à intenção de compra; e $68 \%$ deles tinham intenção provável ou certa de compra.

Ribeiro e Tobinaga (2002) utilizaram o teste de aceitabilidade para avaliar as características sensoriais das amostras de filés
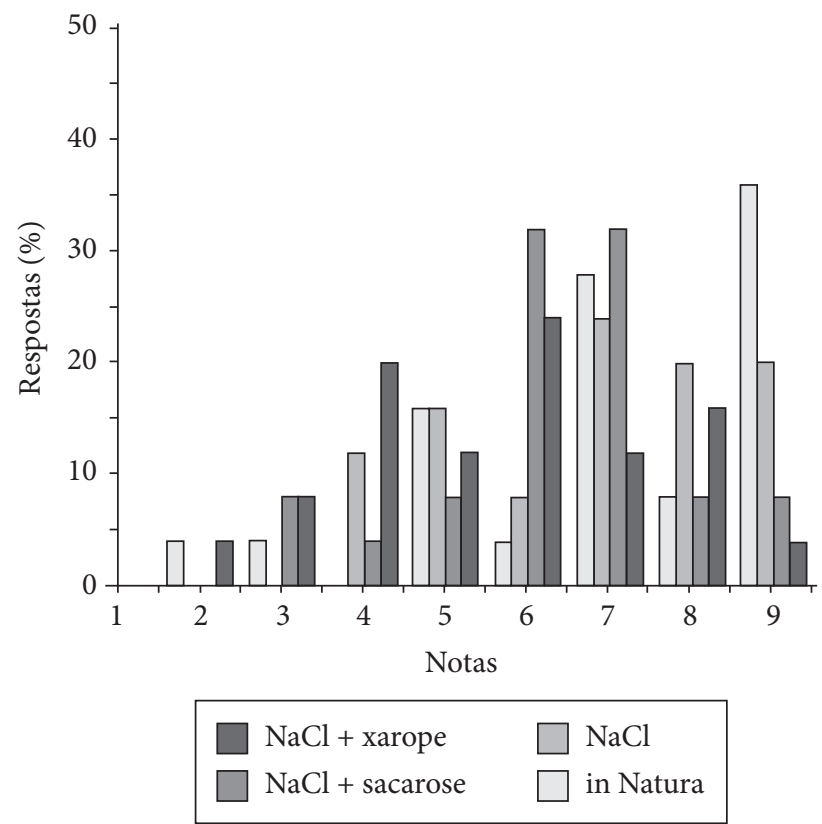

Figura 4. Histograma de frequência dos valores atribuídos ao sabor das amostras de bolinho de peixe mapará com e sem tratamento osmótico.

de peixe matrinchã (Brycon cephalus) secos e defumados. Os resultados mostraram que houve diferença significativa entre as amostras em relação ao odor e a aceitabilidade, que variou de 67,78 a $82,22 \%$, e em relação ao sabor e a aceitabilidade das amostras, que variou de 65,56 a 94,44\%. Observou-se também que houve uma ótima aceitabilidade em relação à textura das amostras, que variou de 73,33 a $92,22 \%$.

\section{Atributo textura}

Para o atributo textura, todas as amostras não apresentaram diferença entre si, a $p<0,05$. Os resultados agregados do teste de média para textura estão apresentados na Tabela 3.

A distribuição das notas de aceitação de cada uma das amostras para o atributo textura sensorial está apresentada na Figura 5.

Verifica-se, na Figura 5, que as amostras foram bem aceitas em relação à textura. As maiores porcentagens estão nas notas 7 e 8 , o que comprova uma boa aceitabilidade das amostras.

No processo de transformação do músculo em carne, o desenvolvimento do rigor-mortis é acompanhado pela degradação do adenosina-trifosfato (ATP) e produção de ácido láctico durante a glicólise anaeróbica, com concomitante queda do $\mathrm{pH}$. Essa degradação facilita a invasão e o desenvolvimento bacteriano, promovendo o amolecimento da carne, produzindo mudanças indesejáveis de textura (SANTOS, 2006).

\section{Impressão global}

Verifica-se na análise de variância dos dados de impressão global (Tabela 2e) que todas as amostras apresentaram diferença 
significativa na aceitação, a $(\mathrm{p}<0,05)$. Os resultados agregados do teste de média para impressão global estão apresentados na Tabela 3.

A distribuição das notas de aceitação de cada uma das amostras para o atributo impressão global está apresentada na Figura 6.

Observa-se, na Figura 6, que a maioria das notas recebidas pelas amostras sem tratamentos e pré-tratadas osmoticamente com soluções binárias e ternárias situa-se na região indicativa de aprovação dos produtos.

Beserra et al. (2003) desenvolveram um produto embutido cozido, tipo apresuntado, contendo diferentes percentuais de carnes suína e caprina de animais de descarte (animais velhos) como forma de agregar valor a essa matéria-prima de pouca aceitação no mercado na forma in natura. As formulações A (100\% carne suína), B (75\% carne suína e 25\% carne caprina), C (50\% carne suína e 50\% carne caprina), D (25\% carne suína e $75 \%$ carne caprina) e E ( $100 \%$ carne caprina) foram submetidas a testes de aceitação global. Os resultados obtidos revelaram existir diferenças significativas $(\mathrm{p}<0,05)$ entre as formulações, constituindo-se a formulação com $75 \%$ carne suína e $25 \%$ carne caprina a de melhor aceitação global dentre aquelas contendo carne caprina.

\section{Aceitação global}

Na Tabela 3, estão apresentadas as aceitabilidades médias dos atributos aparência, aroma, sabor, textura e impressão global de cada uma das amostras avaliadas, juntamente com os resultados da análise de variância e do teste de Tukey.

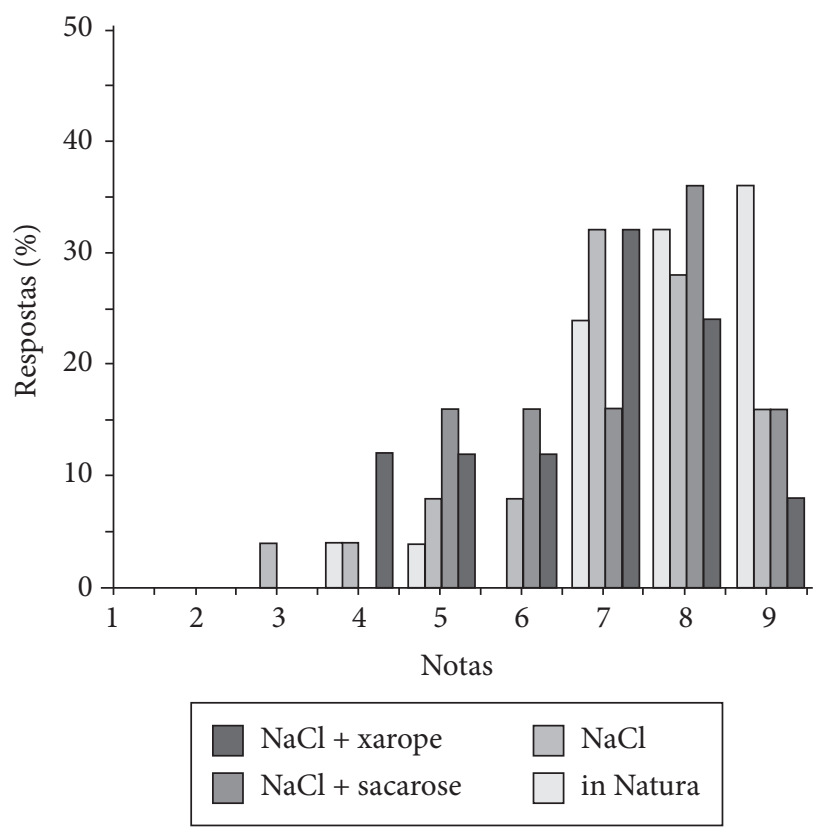

Figura 5. Histograma de frequência dos valores atribuídos à textura sensorial das amostras de bolinho de peixe mapará com e sem tratamento osmótico.
Comparando-se a amostra in natura e a pré-tratada osmoticamente com $\mathrm{NaCl}+$ xarope de milho quanto ao aroma, verifica-se que existe diferença significativa entre si. Porém, as outras amostras não diferiram entre si.

A amostra pré-tratada osmoticamente em xarope de milho foi a que apresentou as menores médias entre as amostras estudadas para todos os atributos. A amostra in natura, segundo os provadores, obteve valores médios de aceitação maiores que os verificados para as amostras pré-tratadas osmoticamente. As aceitações médias para todas as amostras encontram-se na faixa de aceitação.

De acordo com a Tabela 3, as amostras seca, in natura e pré-tratada osmoticamente, não diferem entre si com relação à aparência e à textura no nível de significância de 5\%.

Os comentários feitos pelos provadores foram muito variados. De um modo geral, para a amostra in natura, o sabor foi o atributo que mais agradou aos provadores. Para a amostra pré-tratada com $\mathrm{NaCl}$ e $\mathrm{NaCl}+$ sacarose, os atributos aparência e textura foram os que mais agradaram aos provadores, enquanto que o aroma foi o atributo que menos agradou nestas amostras. Em relação às amostras pré-tratadas com $\mathrm{NaCl}+$ xarope de milho, de acordo com os comentários, o sabor foi sem dúvida, o atributo sensorial que menos agradou aos provadores.

Simões (2007) avaliou bolinho de peixe de tilápia sem tratamento (in natura) e pré-tratado em solução binária $(\mathrm{NaCl})$ e ternária $(\mathrm{NaCl}+$ sacarose) e verificou através da Análise de Variância que não houve diferença significativa entre as amostras analisadas com relação aos atributos aparência, aroma, textura e impressão global, indicando que os provadores não conseguiram perceber diferença significativa entre elas.

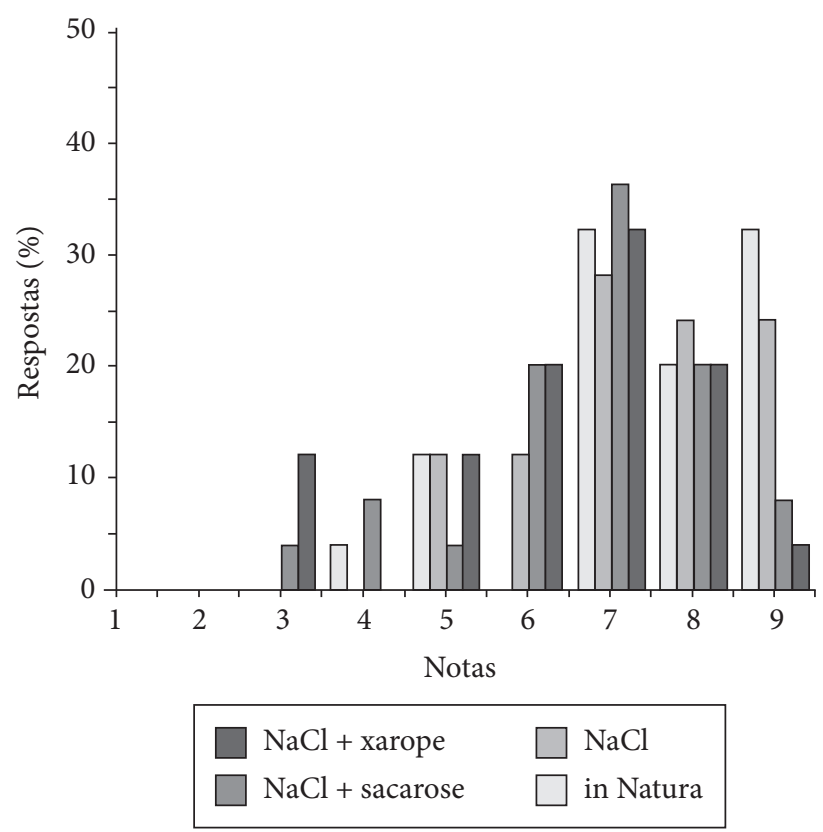

Figura 6. Histograma de frequência dos valores atribuídos à impressão global das amostras de bolinho de peixe mapará com e sem tratamento osmótico. 
Grÿschek et al. (2002) elaboraram fishburgers a partir de carne mecanicamente separada de tilápia nilótica e tilápia vermelha. A análise sensorial com o teste de escala hedônica mostrou aceitação dos produtos. Os resultados comprovaram que os fishburgers elaborados com carne mecanicamente separada não lavada de tilápia vermelha obtiveram menor média de pontos $(5,67)$, com nível de aceitação mantido entre indiferente e gostei ligeiramente. Os demais tratamentos estiveram entre as escalas gostei ligeiramente e gostei moderadamente (entre 6,11 e 6,96).

O histograma de intenção de compra de cada uma das amostras secas está apresentado na Figura 7.

Verifica-se, através da Figura 7, que as amostras pré-tratadas em solução de $\mathrm{NaCl}+$ xarope de milho não obtiveram uma atitude de compra favorável, apresentando quase a metade das respostas na região de não aquisição do produto. As amostras in natura foram as que apresentaram maior intenção de compra e as pré-tratadas em solução de $\mathrm{NaCl}$ apresentam bons índices de intenção de compra entre os provadores, indicando que apresentam um provável potencial de comercialização. Já as amostras pré-tratadas em solução de $\mathrm{NaCl}+$ sacarose apresentaram um maior índice na região de dúvida da compra do produto.

Pezantes (2006) estudou os mecanismos combinados de desidratação osmótica a vácuo (PVOD), defumação líquida e secagem de bonito (Sarda sarda) e comprovou, através da análise sensorial, que o produto seco salgado (PVOD) e o defumado, nos três blocos correspondentes às condições de secagem, não apresentaram diferença significativa $(\mathrm{p}<0,05)$ no grau de aceitação.

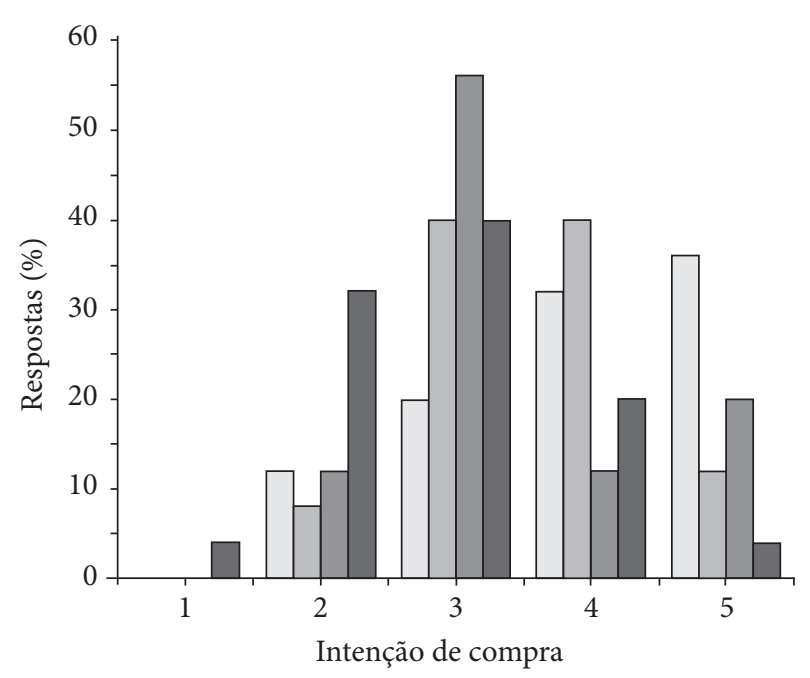

\begin{tabular}{|ll|}
$\square \mathrm{NaCl}$ +xarope & 1 - Eu certamente não compraria \\
$\square \mathrm{NaCl}+$ sacarose & 2 - Eu provavelmente não compraria \\
$\square \mathrm{NaCl}$ & 3 - Eu tenho dúvidas se compraria ou não \\
$\square$ in Natura & 4- Eu provavelmente compraria \\
\hline
\end{tabular}

Figura 7. Histograma de intenção de compra.

\section{Conclusões}

As amostras de bolinho de peixe mapará seco, sem tratamento (in natura) e pré-tratados em solução binária de $\mathrm{NaCl}$ e soluções ternárias de $\mathrm{NaCl}+$ sacarose e $\mathrm{NaCl}+$ xarope de milho, avaliadas sensorialmente tiveram uma boa aceitabilidade em relação à aparência, aroma, sabor, textura e impressão global e também com perspectiva de intenção de compra por parte dos provadores, com exceção da amostra desidratada com $\mathrm{NaCl}+$ xarope de milho.

Os atributos textura e aroma foram os que os provadores mais gostaram nas amostras.

\section{Referências bibliográficas}

ANTUNES, S. G. M. Análise sensorial da carne do escargot "gros gris" (Helix aspersa maxima) pré-cozida e resfriada submetida à radiação gama. 2004. 53 f. Monografia (Especialização em Irradiação de Alimentos) - Universidade Federal Fluminense, Niterói, 2004.

ASSOCIATION OFFICIAL ANALYTICAL CHEMISTS - AOAC. Official Methods of Analysis. 14 ed. Arlington, 1995.

BESERRA, J. F. et al. Desenvolvimento e caracterização físico-química e sensorial de embutido cozido tipo apresuntado de carne de caprino. Ciência Rural, v. 33, n. 6, p. 1141-1147, 2003.

BORGES, A. et al. Qualidade da corvina (Micropogonias furnieri) eviscerada em diferentes períodos de estocagem a $0{ }^{\circ} \mathrm{C}$. Ciência Rural, v. 37, n. 1, p. 259-264, 2007.

CUTRIM, L.; BATISTA, V. S. Determinação de idade e crescimento do mapará (Hypophthalmus marginatus) na Amazônia Central. Acta Amazonica, v. 35, n. 1, p. 85-92, 2005.

GRŸSCHEK, S. F. B.; OETTERER, M.; SPOTO, M. F. Formulação de fishburgers a partir de carne mecanicamente separada de tilápia nilótica (oreochromis niloticus) e tilápia vermelha (oreochromis spp). In: CONGRESSO BRASILEIRO DE CIÊNCIA E TECNOLOGIA DE ALIMENTOS, 18., 2002, Porto Alegre. Anais... Porto Alegre: Sociedade Brasileira de Ciência e Tecnologia de Alimentos, 2002. p. 143-146.

MEDINA VIVANCO, M. L. Desidratação osmótica em soluções ternárias, secagem e transições térmicas de filé de tilápia (Oreochromis niloticus). 2003. 150 f. Tese (Doutorado em Engenharia de Alimentos) - Universidade Estadual de Campinas, Campinas.

NEIVA, C. R. P. et al. Condições do processamento de lingüiça de peixe, utilizando CMS de espécies de peixe subutilizadas. In: CONGRESSO BRASILEIRO DE CIÊNCIA E TECNOLOGIA DE ALIMENTOS, 18., 2002, Porto Alegre. Anais... Porto Alegre: Sociedade Brasileira de Ciência e Tecnologia de Alimentos, 2002. p. 26-30.

OLIVEIRA, N. M. S.; OLIVEIRA, W. R. M.; NASCIMENTO, L. C. Avaliação físico-química de filés de tilápia (Oreochromis niloticus) submetidos à sanitização. Ciência e Tecnologia de Alimentos, v. 28, n. 1, p. 83-89, 2008.

PEZANTES, D. V. Estudo das operações combinadas da desidratação osmótica a vácuo, defumação líquida e secagem em filés de bonito (Sarda sarda). 2006. 223 f. Tese (Doutorado em Engenharia de Alimentos) - Universidade Estadual de Campinas, Campinas.

RAMAllo, L. A.; HUBINGER, M. C.; MASCHERONI, R. H. Transferencia de masa durante deshidratación osmótica de ananá con pulsos de vacío. In: CONGRESO ARGENTINO DE CIENCIA Y TECNOLOGÍA DE LOS ALIMENTOS, 11., 2007, Buenos Aires. Argentina. Anais... Buenos Aires: AATA, 2007. p. 1-3. 
RIBEIRO, S. C. A.; TOBINAGA, S. Avaliação sensorial de filés de matrinchã (brycon cephalus) processados por métodos combinados. Revista Brasileira de Produtos Agroindustriais, v. 4, n. 2, p. 101-106, 2002.

SAMPAIO, G. R. Ocorrência de óxidos de colesterol e análise do perfil lipídico em camarão salgado-seco. 2004. 93 f. Dissertação (Mestrado em Nutrição Humana Aplicada) - Universidade de São Paulo, São Paulo, 2004.

SANTOS, T. M. Avaliação Bacteriológica e Físico-Química (pH e N-BVT) da Carne de Piramutaba, Brachyplatistoma vaillanti (Siluriformes, Pimelodidae), congelada comercializada em Belo Horizonte - MG. 2006. 27 f. Dissertação (Mestrado em Medicina Veterinária) - Universidade Federal de Minas Gerais, Belo Horizonte, 2006.
SIMÕES, M. R. Estudo do processo de desidratação osmótica, secagem e defumação de filés de tilápia Tailandesa (Oreochromis niloticus). 2007. 184 f. Tese (Doutorado em Engenharia de Alimentos) - Universidade Estadual de Campinas, Campinas, 2007.

STEVANATO, F. B. et al. Aproveitamento de resíduos, valor nutricional e avaliação da degradação de pescado. Publicações em Medicina Veterinária e Zootecnia, v. 1, n. 7, p. 1-6, 2007.

TARLADGIS, B. G. et al. A distillation method for the quantitative determination of malonaldehyde in rancid foods. Journal of American Oil Chemists Society, v. 37, n. 1, p. 44- 48, 1960.

TONON, R. V.; BARONI, A. F.; HUBINGER, M. D. Estudo da desidratação osmótica de tomate em soluções ternárias pela metodologia de superfície de resposta. Ciência e Tecnologia de Alimentos, v. 26, n. 3, p. 715-723, 2006. 